\title{
Coupled heat and mass transfer model to simulate hygrothermal behaviour of bio-based materials
}

\author{
M.Asli ${ }^{\text {a }}$, A.Chauchois ${ }^{\text {a }}$, F.Brachelet ${ }^{\text {a }}$, E.Antczak ${ }^{\text {a }}$, D.Defer ${ }^{\text {a }}$ \\ ${ }^{a}$ Univ. Artois, EA 4515, Laboratoire de Génie Civil et géo-Environnement (LGCgE), Béthune, F-62400, France.
}

\begin{abstract}
Natural fibre materials, with bio-sourced characteristics, are advanced materials used in building construction and renovation. They have various advantages, such as good thermal insulation, high moisture buffering, and low impact environmental. Our research focuses on three different natural fibre materials: hemp concrete, wood wool, and sheep wool. Thus, to analyse their hygrothermal behaviour, we provide a numerical simulation and a comparative study.
\end{abstract}

Keywords: hemp concrete, wood wool, sheep wool, bio-based materials, modelling, heat and mass transfer, numerical simulation.

\section{Introduction}

Bio-based materials constitute an efficient solution to reduce energy consumption, and consequently save energy and resources [1]. They have various benefits in building envelope renovation and new buildings construction. The major advantage of using the bio-based materials is their good thermal insulating properties [2][3] .In addition, they procure high moisture buffing capacity and a good balance between low mass and storage capacity [4], when compared to the classical insulation materials. In this paper, we numerically simulate the hygrothermal behaviour of bio-based materials using Comsol Multiphysics. The studied problem constitutes of numerical comparative analysis of hygrothermal behaviour of hemp concrete manufactured with wood wool and sheep wool. The experimental setup is represented by materials samples, which they are exposed to variable heat flux and humidity, taking into consideration the coupled heat and mass effect.

\section{Theoretical approach \\ A. Overview}

Humidity is one of the main factors affecting thermal comfort of the envelope [5]. Moreover, when accompanied by a high temperature, it causes an unpleasant feeling of heaviness and suffocation. It also has an impact on structures construction and human health [6]. The phenomenon of moisture adsorption, by the bio-based materials, can degrade the materials quality (thermal insulation, mechanical resistance, etc...). Particularly, in the condensation case, humidity has a great influence on the habitat thermal performance related to the heating and cooling system consumption [7]. Therefore, the study of coupled heat and mass transfer within the biobased material is necessary and essential to evaluate the hygrothermal behaviour. Consequently, this helps to improve the thermal performance and reduce the energy consumption for winter heating and summer cooling $[8]$.
Several studies were carried out to investigate the coupled heat and mass transfer in porous media by Philip De Vries [9] and Whitaker [10] .In general, we identify two approaches, the first at a microscopic scale, as the works of Glaser [11], in order to better understand the complex phenomena that occur simultaneously, for example water and water vapour diffusion. The second approach is at a macroscopic scale, as the works of Phillipe De Vries [9] and Whitaker [10] . In the latter, we assume that the solid matrix is considered homogeneous. The media is then characterized by a representative elementary volume (REV).

\section{B. Mathematical model \\ 1) Basic Model}

Mechanisms of mass transport within bio-based material have been extensively investigated [12]. Most works were based on the model proposed by Philip and De Vries [9], Fourier's law, Fick's and Darcy's law. The difference between them is in the particular basics assumptions. Subsequently, the model of Philip and De Vries [9] is taken as the basic model for our numerical simulation to predict the hygrothermal behaviour of three bio-based material.

Philip and De Vries model [9] takes into account moisture transport under two phases (liquid and vapour). It assumes that the vapour phase moves under a gradient of partial vapour pressure and the water phase moves under capillarity. With these considerations, the mass conservation equation becomes:

$$
\frac{\partial \theta}{\partial t}=\frac{\partial}{\partial x}\left(D_{\theta} \frac{\partial \theta}{\partial x}\right)+\frac{\partial}{\partial x}\left(D_{\tau} \frac{\partial T}{\partial x}\right)
$$

Where $\theta$ is the water content, $\left(D_{T}\right.$ and $\left.D_{\theta}\right)$ are, respectively, the mass transport coefficients associated to temperature and moisture content gradient.

The associated boundary conditions given are by equations 2 and 3, for the external and internal sides, respectively $(\mathrm{x}=0, \mathrm{x}$ $=\mathrm{L}$ ).

$$
\begin{aligned}
& \rho_{t}\left(D_{T} \frac{\partial T}{\partial x}+D_{\theta} \frac{\partial \theta}{\partial x}\right)=h_{\text {met }}\left(\rho_{\text {rase }}-\rho_{\text {vises }}\right) \\
& \rho_{2}\left(D_{T} \frac{\partial T}{\partial x}+D_{\theta} \frac{\partial \theta}{\partial x}\right)=h_{m, i} \quad\left(\rho_{k, j, i}-\rho_{y, a i}\right)
\end{aligned}
$$

Where $\mathrm{h}_{\mathrm{m}, \mathrm{e}, \mathrm{i}}$ is the convective mass coefficient from external and internal side, the subscripts a and $\mathrm{s}$ represent the adjacent air and solid surface of the material, respectively. While the subscripts e and i correspond, respectively, to the external and internal neighbouring environment (a) or solid surface (s).

Equation (4) describes the heat transfer in porous media and is derived from the principle of energy conservation. It is represented by Fourier's equation and a heat source 
accounting for the phase change within the pore. In 1-D equation (4) is written as:

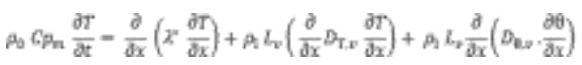

where $\rho_{0}$ is the solid matrix density, $\mathrm{L}_{\mathrm{v}}$ is the latent heat of vaporisation, $\rho_{1}$ represents the water density, and $\mathrm{C}_{\mathrm{pm}}$ is the specific heat. The latter is calculated as the average specific heat of solid matrix and liquid phase $\mathrm{C}_{\mathrm{pm}}=\mathrm{C}_{\mathrm{p} 0}+\mathrm{C}_{\mathrm{pl}}, \lambda^{*}$ and is equivalent to the thermal conductivity function of moisture content. $\mathrm{D}_{T, v}$ and $\mathrm{D}_{\theta, v}$ are the vapour phase transport coefficients associated to temperature and moisture content gradient, respectively.

The associated boundary conditions for the external and internal sides are, respectively:

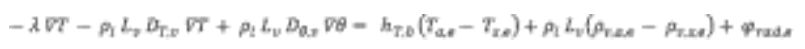

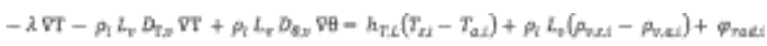

Where $\rho_{\mathrm{v}, \mathrm{e}, \mathrm{i}}$ is the air density from external and internal side, $\varphi_{\text {rad,e, }}$ is a radiation term which is assumed negligible in our study case.

\section{2) Transport coefficients}

The relationships relating transport coefficients of mass with transport coefficients of vapour and liquid phase are:

$$
\begin{aligned}
& \mathrm{D}_{T}=\mathrm{D}_{T, l}+\mathrm{D}_{T, v}\left[\mathrm{~m}^{2} /(\mathrm{s} . \mathrm{K})\right] \\
& \mathrm{D}_{\theta}=\mathrm{D}_{\theta, l}+\mathrm{D}_{\theta, v}\left[\mathrm{~m}^{2} / \mathrm{s}\right]
\end{aligned}
$$

According to Philip and De Vries [9], the transport coefficients associated to moisture gradient are related to water vapour permeability $\delta 0$ and specific hygric capacity $\xi$, which is the slope of sorption curve:

$$
D_{\theta}=\frac{\delta_{a} P_{u s g}}{\rho_{0}} \frac{1}{\xi}
$$

$\delta_{0}=\left(\delta_{\mathrm{a}} / \mu\right), \delta_{\mathrm{a}}$ is the vapour permeability and is equal to $2 \times 10^{-}$ ${ }_{10}(\mathrm{~kg} / \mathrm{m}$.s.Pa $)$, and $\mu$ is the material vapour diffusion resistance factor. $\mathbf{P}_{v, s}$ is the saturation vapour pressure.

$$
D_{T, V}=\frac{\delta_{a} \varphi}{\rho_{\sharp}} \frac{\mathrm{d} P_{u, s}}{\mathrm{~d} T}
$$

The other coefficients are neglected to simplify the preliminary study case of the three previously described materials.

\section{Materials}

\section{A. Hemp concrete}

Hemp is a plant of the "cannabis" family. It is a particular plant due to its stem size and fibres. The hemp provides two types of materials "hemp hurds" and "hemp fibres". Hemp concrete is a porous material obtained by mixing a lime binder, hemp fibres (shives) and water. The high porosity of hemp concrete is due to the presence of various capillaries, whose diameters range between 10 and $40 \mu \mathrm{m}$, as shown Figure 1. In our work, we study the hygrothermal behaviour of manufactured hemp concrete (Figure 2).

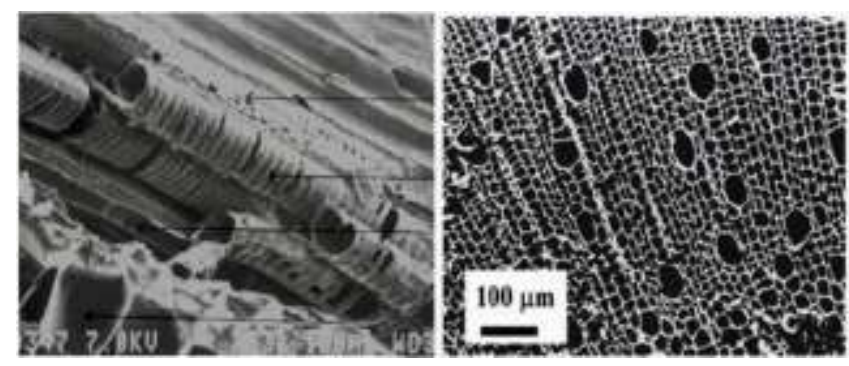

Figure 1. Microscopic electronic picture of hemp particle (Garcia-jaldon 1995)

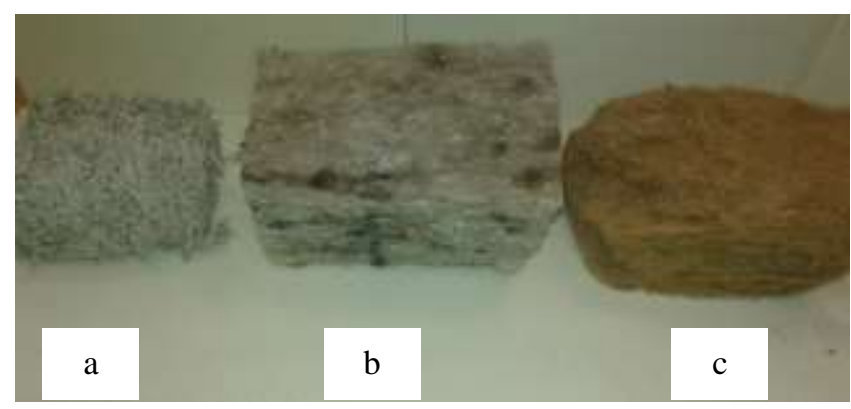

Figure 2. Photo of hemp concrete (a), sheep wool (b) and wood wool(c) samples tested in laboratory

The majority of the characteristics are measured in the laboratory and the rest are taken from the literature.

\section{B. Wood wool}

Wood wool it is an insulating material made of wood fibres. The wood fibres are manufactured through a grinding process with water mixing. Therefore, to guarantee the accuracy of the correct model parameters, the characteristics are measured in the laboratory. Figure 3 presents a photo of the wood wool sample tested in our laboratory.

\section{Sheep wool}

Sheep wool is an insulation material, produced from raw material with nature and variable quality. Sheep wool can be brute or manufactured material. In our case, the sheep wool is manufactured. Figure 4 presents a sample of the sheep wool tested in our laboratory.

\section{Experimentation approach}

\section{A. Water vapour sorption}

The water vapour sorption test was performed according to the discontinuous method [13]. The samples of hemp concrete, wood wool, and sheep wool are placed in climatic chamber [APT.lineTM MKFT (E3.1) Binder Gmbh], where the conditions of temperature and relative humidity are controlled. The temperature range varies between $0{ }^{\circ} \mathrm{C}$ and $50{ }^{\circ} \mathrm{C}$, and the relative humidity range varies between $0 \%$ and $97 \%$. The uncertainties are evaluated by the supplier at $0.5^{\circ} \mathrm{C}$ and $2 \%$, respectively. The water content is determined for successive stages of relative humidity increasing then decreasing with constant temperature of $23{ }^{\circ} \mathrm{C}$ (isothermal test). For each materials type, three samples were performed, which is the minimum required by the standard [13]. The samples are 
waited until reaching the steady state. We consider that, after three successive loading during $24 \mathrm{~h}$, if the difference is lower than $0.1 \%$ of the mass, therefore the equilibrium is reached, and the water content is calculated as:

$$
\theta=\frac{m-m_{0}}{m_{0}}
$$

where $\mathrm{m}_{0}$ is the mass of sample in the dry state, $\mathrm{m}$ is the mass sample at steady state. The isothermal sorption is a very long test, it may take more than 1 year (sorption-desorption) it depends on the material nature. Figure 5 shows the kinetic sorption of wood wool for the adsorption branch (increasing stage).

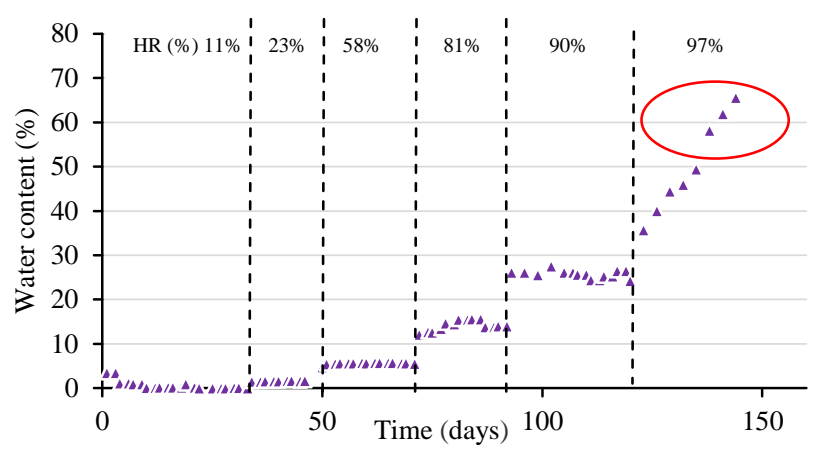

Figure.5. Kinetic of sorption isotherm wood wool

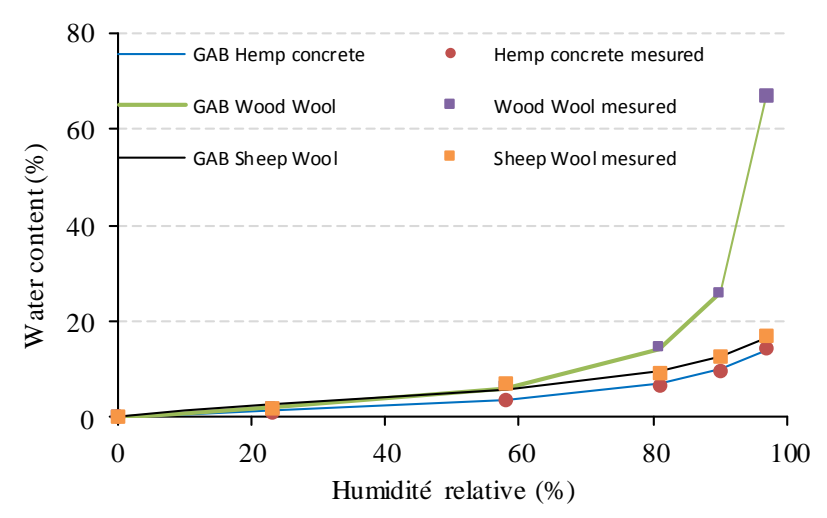

Figure.6. Sorption isotherm Hemp concrete, Wood wool and Sheep wool

\section{B. Sorption models}

Several models have been developed to establish empirical expressions to fit the sorption curve. Langmuir model [14], GAB [15] and BET are the most accurate models:

$$
\begin{array}{lll}
\text { Langmuir model: } & \theta=\theta_{m}+\frac{C \cdot H R}{1+C \cdot H R} \\
\text { BET model: } & \theta=\frac{C \cdot \theta_{m} \cdot H R}{(1-H R) \cdot(1-H R+C \cdot H R)} \\
\text { GAB model: } & \theta=\frac{C \cdot \theta_{m} \cdot K \cdot H R}{(1-K \cdot H R) \cdot(1-K \cdot H R+K \cdot C \cdot H R)}
\end{array}
$$

where $\theta_{\mathrm{m}}$ is the water content corresponding to the monolayer sorption for each model, $\mathrm{HR}=\left(\mathrm{P}_{\mathrm{v}} / \mathrm{P}_{\mathrm{s}}\right)$ is the relative humidity, $\left(\mathrm{P}_{\mathrm{v}}\right.$ and $\left.\mathrm{P}_{\mathrm{s}}\right)$ are the vapour partial pressure and saturation pressure, and ( $\mathrm{C}$ and $\mathrm{K})$ are the model parameters.

$$
\mathrm{C}=\exp \frac{E_{a}-E_{m}}{R \cdot T} \quad \mathrm{k}=\exp \frac{E_{l}-E_{m}}{R \cdot T}
$$

$E_{a}$ is the heat of adsorption, $E_{l}$ is the heat liquefaction, and $E_{m}$ is the binding energy. In the rest of this work, the GAB model will be applied based on the results obtained from water vapour sorption test. The GAB model covers a wide range of relative humidity $(0.05<\mathrm{HR}<0.9)$, while the other models cover a narrow range.

In order to obtain the different parameters of the GAB model a least-square method is being implemented:

$$
\sum\left(\theta_{\mathrm{i}}-\theta_{\text {exp }, \mathrm{i}}\right)=\text { minimum }
$$

$\theta_{\text {exp,i }}$ is the water content measured at the relative humidity $\mathrm{i}, \theta_{\mathrm{i}}$ is water content calculated by the GAB model.

Figure 6 shows the experimental data of sorption isotherm measured for the three tested materials: hemp concrete, wood wool, and sheep wool. The fitting curves are given by GAB model. According to IUPAC classification [16], the sorption curves are classified as type II, which means that the type of materials are non-porous or macro-porous media. This confirms the nature of these three fibrous materials. From these curves, we can observe three parts of water content evolution. The test started from $0 \%$ of water content, which is the initial condition assumed (dry material). The first part is at low relative humidity $\varphi<23 \%$, the water contents for these three materials are practically the same. The second part is when the relative humidity range varies between $23 \%<\varphi<$ $60 \%$, the behaviour of these three materials is slightly different. Mainly, the water content absorbed by wood wool is higher than the two others. The last part, is when relative humidity range varies at high hygroscopic region $60 \%<\varphi<$ $97 \%$, the water absorbed for the three materials increase rapidly in this region. For the wood wool the water content is hugely absorbed until (70\%). Figure 5 can be explained by the effect of the condensation that emerges (the water vapour is transformed into water). However, the sheep wool shows a value higher than hemp concrete. Hence, the sheep wool is slightly more hygroscopic than the hemp concrete.

The parameters of the GAB model are given in Table I. the monomolecular water content $\theta_{\mathrm{m}}$ and the energy values ( $\mathrm{C}$ and $\mathrm{K})$. The monomolecular water content of sheep wool is higher than the two other materials. However, the energy constant value $\mathrm{K}$ of wood wool is superior to that of the hemp concrete and sheep wool. The error value shows the high accuracy of the GAB model fitting.

\section{Thermophysical properties}

Several procedures can be performed in the laboratory to characterize the studied materials, e.g guarded hot plate method to determine the thermal conductivity in steady state, and apparent density measurement to determine dry and apparent densities. The majority of these tests are in progress and may take more or less time. For this reason, we decided to use values available from the literature e.g for wood wool [17], sheep wool[18], and hemp concrete [3].

To simplify the study case, some parameters are taken as constant values. Numerical investigation of hygrothermal behaviour of the three kinds materials using Philip and De Vries model [9] is implemented in Comsol Multiphysics. 
The model's parameters are summarized in table II, with the transport coefficients reported in Figure 7.

Table I. GAB parameters for three the three kind of materials.

\begin{tabular}{|c|c|c|c|c|}
\hline Materials & $\mathbf{C ~ ( - )}$ & $\mathbf{K}(-)$ & $\boldsymbol{\theta}_{\mathbf{m}}(\mathbf{k g} / \mathbf{k g})$ & Error $(\%)$ \\
\hline Hemp concrete & 2.56 & 0.8541 & 0.0259 & 3.04 \\
\hline Wood wool & 3.37 & 0.9843 & 0.0307 & 1.48 \\
\hline Sheep wool & 7.36 & 0.8325 & 0.033 & 3.03 \\
\hline
\end{tabular}

Table II. Simulation parameters of three the three kind of materials.

\begin{tabular}{|c|c|c|c|c|}
\hline Materials & $\begin{array}{c}\text { Thermal } \\
\text { conductivity } \\
{[\mathbf{W} /(\mathbf{m} \cdot \mathbf{K})]}\end{array}$ & $\begin{array}{c}\text { Dry } \\
\text { density } \\
{\left[\mathbf{k g} / \mathbf{m}^{3}\right]}\end{array}$ & $\begin{array}{c}\text { Specific } \\
\text { heat } \\
[\mathbf{J} / \mathbf{k g . K})]\end{array}$ & $\begin{array}{c}\boldsymbol{\mu} \\
\text { factor } \\
{[-]}\end{array}$ \\
\hline $\begin{array}{c}\text { Hemp } \\
\text { concrete }\end{array}$ & $\begin{array}{c}0.1058+ \\
0.77 * \theta\end{array}$ & 450 & 1100 & 7.5 \\
\hline Wood wool & 0.1 & $400-600$ & 2000 & 24 \\
\hline Sheep wool & 0.033 & $25-45$ & 1720 & $1-2$ \\
\hline
\end{tabular}

\section{Case study}

The simulations are made for the three studied materials, hemp concrete, wood wool and sheep wool, in order to evaluate the hygrothermal behaviour of natural fibrous materials.

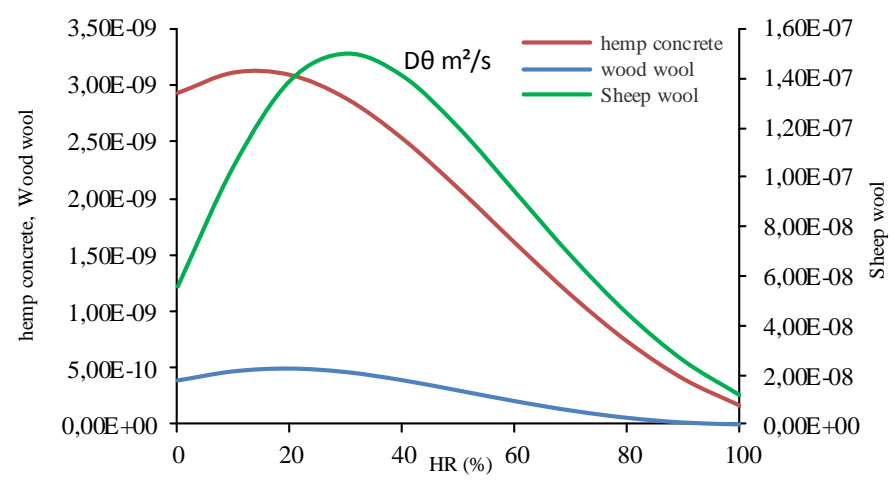

Figure 7. Thermal diffusivity versus relative humidity of hemp concrete, wood wool, sheep wool.

The materials samples simulated have an area of $(200 \times 100$ $\mathrm{mm}^{2}$ ) and a thickness of $200 \mathrm{~mm}$, exposed to climatic conditions. Figure 10 ( $a$ and $b$ ), shows that the choice of conditions was according to the Nordtest Protocol for the specific evaluation of moisture Buffering potential. At constant initial conditions: $\mathrm{T}=21^{\circ} \mathrm{C}, \mathrm{HR}=0.5 \%$ is imposed. The first study case is performed for $48 \mathrm{~h}$. The climatic conditions are represented by a sinusoidal temperature variation of $25{ }^{\circ} \mathrm{C}\left(10{ }^{\circ} \mathrm{C}\right.$ of amplitude), and a constant value for the relative humidity ( $\mathrm{HR}=50 \%$ ) as illustrated in Figure 8a. However, the second study case simulation is the opposite case, that is consisted to produce isothermal conditions, and this is by keeping constant temperature value at $\left(23^{\circ} \mathrm{C}\right)$ and give a step variation of air relative humidity increase from 50 $\%$ to $75 \%$, and then decrease from $75 \%$ to $35 \%$ during 10 days (Figure $8 b$ ). Equations (1 and 4) are implemented in COMSOL Multiphysics. Simulations are performed by solving the coupled nonlinear partial differential equations in the "PDE Modes", which gives a large flexibility to dimensioning the equations ( 1 and 4$)$, and writing the boundary conditions $(2,3,5$ and 6$)$. The simulations are run with the materials properties reported in table I and II, and the coefficients reported in Figure 7. The mesh size is $2 \mathrm{~mm}$ and the time step is $100 \mathrm{~s}$.
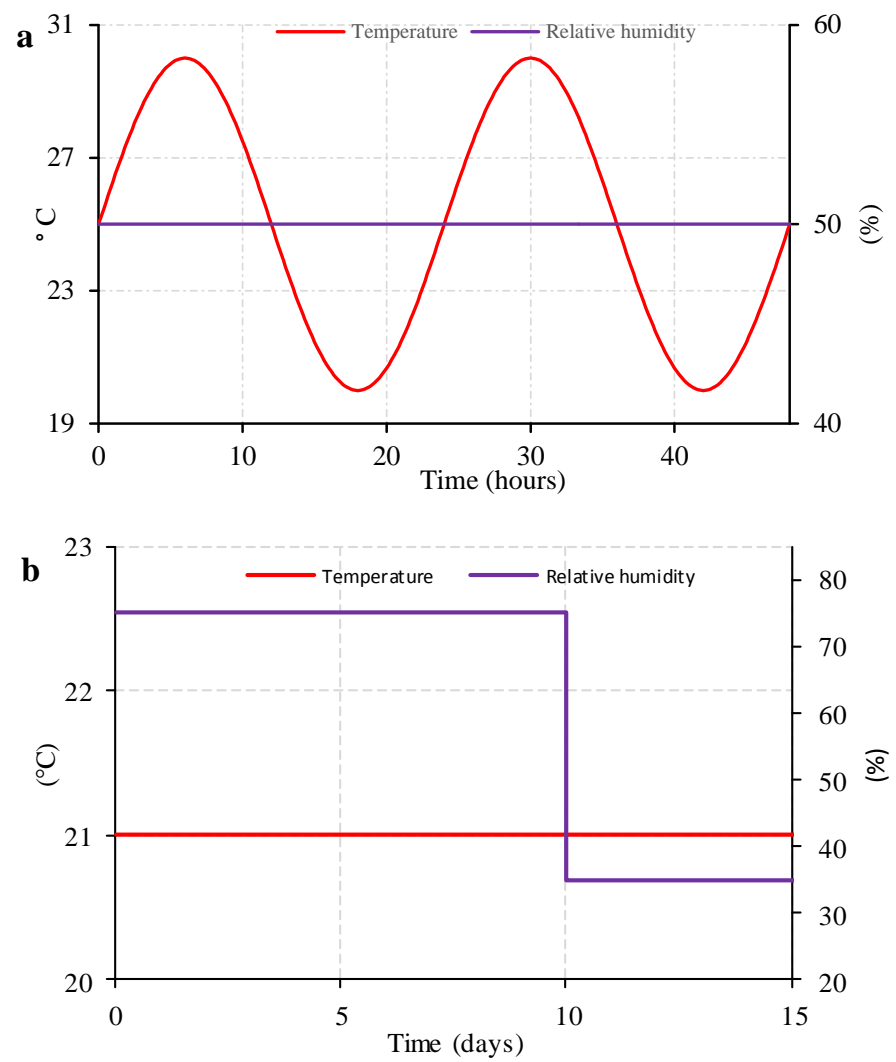

Figure $8(a$ and $b)$. Climatic conditions of the temperature and the relative humidity.

\section{Results}

The results for the first study case of temperature variations at depth of $50 \mathrm{~mm}$ are presented in Figure 9. The first simulation configuration was performed for $48 \mathrm{~h}$. In this short period, we can observe heat transfer phenomena within the materials, the temperature inside the material follow the air temperature variation with damping and phase shift. The materials responses are very different. When the air temperature varies with $10{ }^{\circ} \mathrm{C}$ of amplitude, temperature varies at depth $50 \mathrm{~mm}$ with an amplitude of $\left(9.11^{\circ} \mathrm{C}, 4.58^{\circ} \mathrm{C}\right.$, $3.07{ }^{\circ} \mathrm{C}$ ) for sheep wool, hemp concrete and wood wool respectively. This means that external temperature variation is dampened by about $(8.9 \%, 54.2 \%$, and $69.3 \%)$ for the three materials respectively. Same remark can be addressed for the time lags, $(1: 52 \mathrm{~h}, 4: 30 \mathrm{~h}, 7: 33 \mathrm{~h})$ values were registered for sheep wool, hemp concrete and wood wool, respectively. This can be explained by the low thermal inertia of sheep wool (42500 J/ $\mathrm{kg}^{-1} \mathrm{~K}^{-1}$ ), compared to the hemp concrete and wood wool $\left(495000 \mathrm{~J} / \mathrm{kg}^{-1} \mathrm{~K}^{-1}, 1200000 \mathrm{~J} / \mathrm{kg}^{-1} \mathrm{~K}^{-1}\right)$, respectively. The second study case was performed for 15 days, in order to observe the mass transfer (long test), then, evaluate the hygrothermal behaviour due to the relative humidity change. The simulation results of relative humidity at depth of (15 and 50) $\mathrm{mm}$ within materials are presented in figure 10 ( $\mathrm{a}$ and $\mathrm{b}$ ) respectively. 


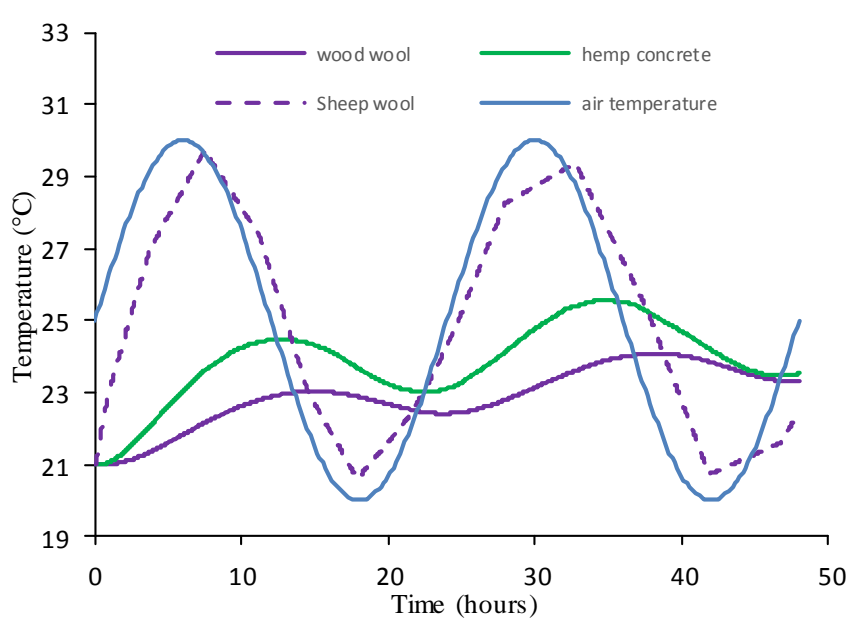

Figure 9. Temperature profile within materials at $x=50 \mathrm{~mm}$ a

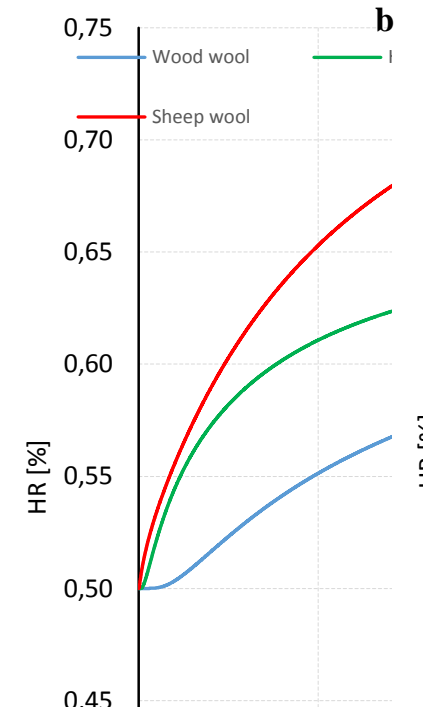

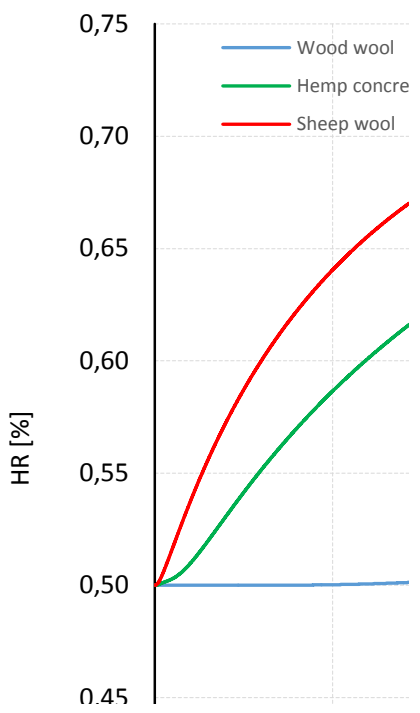

Figure $10(a, b)$. Relative humidity variation versus time within materials at $\mathrm{x}=(15,50 \mathrm{~mm})$ respectively.

The initial relative humidity was set at $50 \%$ for the three materials. We first observe that the relative humidity within sheep wool has reached the quasi-steady state more quickly than the hemp concrete and wood wool. In the adsorption phase, we observed that for hemp concrete and sheep wool, at depth $15 \mathrm{~mm}$, the relative humidity increases very fast during first 2 days before establishing a quasi-steady state. This is due to the thermal diffusion coefficient which is very high at a low relative humidity value $\mathrm{D}_{\theta}=2.10^{-9} \mathrm{~m}^{2} / \mathrm{s}(\varphi<55 \%)$ Figure.7 shows that, for the wood wool, the relative humidity keeps increasing until reaching $57 \%$ at depth $15 \mathrm{~mm}$. This can be explained by the high water vapor resistance factor $(\mu=24)$ for wood wool. The desorption phase begins, where the air relative humidity decreases, and it flows within the material in order to reach the steady state. The slopes of the sorption stage curves are different from those of the desorption curves. This means the materials adsorb and desorb water vapor differently, which is agrees with Figure .7. The diffusion coefficients $\left(D_{\theta}\right)$ are high at lower relative humidity. The relative humidity evolution at depth $50 \mathrm{~mm}$ is presented in Figure 10.b. The time lags needed to reach $60 \%$ of relative humidity are (94:08 h, 178:2) for sheep wool and hemp concrete respectively. This is the time taken for the moisture to be transferred from the surface to the materials at depth $50 \mathrm{~mm}$. Concerning the wood wool, the relative humidity never reach $60 \%$ during the 10 days for the adsorption stage, this is due to the high factor of water vapor resistance $(\mu=24)$.

\section{Acknowledgement}

The work is done as part of the project "P2AR" financed by the region Nord Pas De Calais.

\section{References}

[1] S. Pretot, F. Collet, and C. Garnier, "Life cycle assessment of a hemp concrete wall: Impact of thickness and coating," Building and Environment, pp. 223-231, 2014.

[2] S. Elfordy, F. Lucas, F. Tancret, and Y. Scudeller, "Mechanical and thermal properties of lime and hemp concrete ("'hempcrete") manufactured by a projection process," Construction and Building Materials, pp. 2116-2123, Oct-2008.

[3] V. Cerezo, "Propriétés mécaniques, thermiques et acoustiques d'un matériau à base de particules végétales: approche expérimentale et modélisation théorique," 2005.

[4] F. Collet and S. Pretot, "Experimental investigation of moisture buffering capacity of sprayed hemp concrete," Construction and Building Materials, p. Volume 36, Pages 58-65, Nov-2012.

[5] L. Fang, G. Clausen, and P. O. Fanger, "Impact of temperature and humidity on perception of indoor air quality," INDOOR AIR, pp. 80 90, 1998.

[6] A. V. Arundel, E. M. Sterling, J. H. Biggin, and T. D. Sterling, "Indirect Health Effects of Relative Humidity in Indoor Environments," Environmental Health Perspectives, pp. 351-361,.

[7] N. Mendes, I. Ridley, R. Lamberts, P. C. Philippi, and K. Budag, "Umidus: A PC Program For The Prediction Of Heat And Mass Transfer In Porous Building Elements In.," International Conference on Building Performance Simulation (IBPSA '99), Kyoto., 1999.

[8] A. Tran Le D., "Etude des transferts hygrothermiques dans le béton de chanvre et leur application au bâtiment (sous titre: simulation num'erique et approche expérimentale)," Uiversité de reims champagne-ardenne, 2010.

[9] J.R. Philip and D.A. DE Vries, "Moisture Movement in Porous Materials under Temperature Gradients," Transactions, American Geophysical Union, pp. 222-232, Apr-1957.

[10] S. Whitaker, "Simultaneous Heat, Mass, and Momentum Transfer in Porous Media: A Theory of Drying," ADVANCES IN HEAT TRANSFER, 1977.

[11] H. Glaser, "Graphisches Verfahren zur Untersuchung von Diffusionsvorglinge. Kalfetechnik," pp. 345-349, 1959.

[12] A. Tran Le D., C. Maalouf, T. . Mai, E. Wurtz, and F. Collet, "Transient hygrothermal behaviour of a hemp concrete building envelope," Energy and Buildings, pp. 1797-1806, 15-May-2010.

[13] "NF EN ISO 12571 Hygrothermal performance of building materials and products- Determination of hygroscopic sorption properties," 25Oct-2013.

[14] I. Langmuir, "The adsorption of gases on plane surfaces of glass, mica and Platinum," Journal of the American Chemical Society, pp. 1361$1403,1918$.

[15] E. Guggenheim, "Application Of Statistical Mechanics," Oxford University Press, 1966.

[16] K. S. W. Sing, "Reporting physisorption data for gas/solid systems with special reference to the determination of surface area and porosity," International Union of pure and applied chemistry, pp. 2201-2218, 1982.

[17] O. Vololonirina, M. Coutand, and B. Perrin, "Characterization of hygrothermal properties of wood-based products - Impact of moisture content and temperature," Construction and Building Materials, pp. 223-233, 2014.

[18] T. M. Tuzcu, "Hygro-Thermal Properties of Sheep Wool Insulation," Civil Engineering Faculty Delft University of Technology, 2007. 